\title{
PROPERTIES OF HIGH-ALLOYED METAL DEPOSITED USING ELECTROSLAG TWO-STRIP METHOD
}

\author{
A.A. BABINETS \\ E.O. Paton Electric Welding Institute, NASU \\ 11 Kazimir Malevich Str., 03680, Kiev, Ukraine. E-mail: office@paton.kiev.ua
}

\begin{abstract}
During surfacing of corrosion-resistant layer on the parts of power and chemical equipment it is often necessary to obtain a specified chemical composition and properties of deposited metal already in the first layer. The influence of current, voltage and deposition rate as well as the sizes of gap between the strips on the stability of electroslag process, geometric dimensions of deposited beads and volume of base metal in the deposited metal were investigated. The range of surfacing modes using two strips of stainless steel of $0.5 \times 60 \mathrm{~mm}$ section was determined, in which a stable electroslag process with a good formation of deposited metal and minimum penetration of the base metal in the range of 7-9 \%, i.e. $I_{\mathrm{s}}=1400-1500 \mathrm{~A}, U_{\mathrm{s}}=32-33 \mathrm{~V}$ and $v_{\mathrm{d}}=14-17 \mathrm{~m} / \mathrm{h} ; 16 \mathrm{~mm}$ gap between the strips, is observed. The mechanical properties of metal, deposited at these modes using strips ESAB OK Band 309LNb ESW and Sv-08Kh19N10G2B under flux ESAB OK 10.10, are at a sufficiently high level and meet the requirements specified to them. The obtained results may be used in selection or development of materials and technologies of anticorrosive surfacing of parts of power and chemical equipment. 11 Ref., 4 Tables, 5 Figures.
\end{abstract}

Keywords : electroslag surfacing, deposited metal, electrode strip, bimetal, corrosion-resistant layer, surfacing modes, mechanical properties

For protection against corrosion of parts of power and chemical equipment, electric arc surfacing of high-alloyed metal on low carbon steel is widely used performed under the layer of flux $[1,2]$. Basically, surfacing is performed using one electrode strip of $0.5-0.8 \mathrm{~mm}$ thickness and $50-70 \mathrm{~mm}$ width, that depending on surfacing modes, provides the efficiency of $10-35 \mathrm{~kg} / \mathrm{h}$ [2]. As the volume of base metal (VBM) in the deposited one amounts to $15-25 \%$, then to provide the required chemical composition of corrosion-resistant layer it is necessary to deposit two or more layers, that may lead to accumulation of microdefects, increase in the level of residual stresses, chemical and structural heterogeneity [3]. Under the difficult operation conditions, these factors can negatively influence the stability of deposited metal against the formation and development of hot cracking and intercrystalline corrosion, which negatively affects the service life of parts [4].

One of the ways for solving this problem is the use of methods and materials for surfacing, which would provide a minimum penetration of base metal. One of these methods is electroslag two-strip surfacing developed at the E.O. Paton Electric Welding Institute. According to some data [5-7], this method allows obtaining the required chemical composition of the deposited metal already in the first layer, that is particularly important in producing bimetallic products by surfacing of high-alloyed austenite steels on conventional structural steel. At the same time, the corrosion-resistant layer must also possess the necessary mechanical properties like sufficient strength, high ductility and impact toughness.

(C) A.A. BABINETS, 2016
The aim of this work is to investigate the influence of current, voltage and deposition rate, as well as dimensions of the gap between the electrode strips on stability of electroslag process, geometric dimensions of deposited beads and VBM.

The scheme of electroslag two-strip surfacing process is shown in Figure 1. In the process two electrode strips are fed to the welding head at the same rate. The current supply is carried out through the copper insert located between the strips and thus providing a certain gap. The protection of surfacing area from atmosphere is carried out by electrically conductive flux. During surfacing at the first moment of time between the elec-

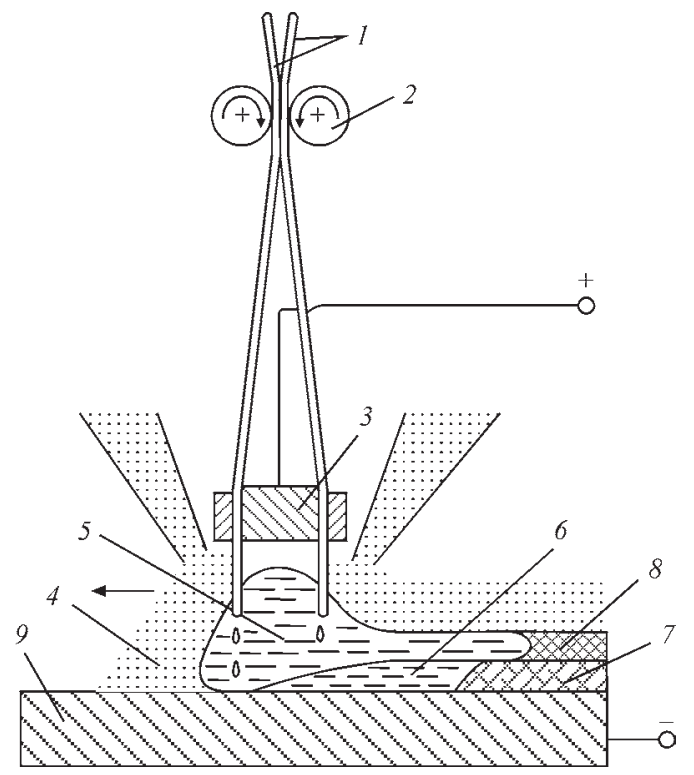

Figure 1. Scheme of electroslag two-strip surfacing [4]: 1 - electrode strips; 2 - feeding rollers; 3 - copper insert; 4 - slag (flux); 5 - slag pool; 6 - metal pool; 7 - deposited metal; 8 slag crust; 9 - billet 
Table 1. Chemical composition of strips for anticorrosion surfacing and volume fraction of $\delta$-ferrite in the corresponding deposited metal [6-10]

\begin{tabular}{|c|c|c|c|c|c|c|c|}
\hline \multirow{2}{*}{ Grade of strip } & \multicolumn{6}{|c|}{ Volume fraction of elements, $\%$} & \multirow{2}{*}{$\begin{array}{l}\text { Volume fraction } \\
\text { of } \delta \text { - ferrite, } \%\end{array}$} \\
\hline & $\mathrm{C}$ & Mn & $\mathrm{Si}$ & $\mathrm{Cr}$ & $\mathrm{Ni}$ & Other & \\
\hline Sv-03Kh22N11G2B & $\leq 0.03$ & 1.7 & 0.4 & 22 & 11.0 & $1.0 \mathrm{Nb}$ & $7-9$ \\
\hline Sv -08Kh19N10G2B & 0.09 & 1.8 & 0.4 & 20 & 10.4 & $1.3 \mathrm{Nb}$ & $2-8$ \\
\hline Np-02Kh22N11G & $\leq 0.02$ & 1.5 & 0.4 & 22 & 11.0 & - & $2-6$ \\
\hline LS-02Kh21N12G & $\leq 0.02$ & 1.2 & 0.4 & 21 & 11.5 & - & $2-8$ \\
\hline LS-02Kh21N12G2B & $\leq 0.02$ & 1.7 & 0.4 & 21 & 11.5 & $0.3 \mathrm{Nb}$ & $2-8$ \\
\hline ESAB OK Band 309L ESW & 0.015 & $1.0-2.5$ & $\leq 0.5$ & $21-22$ & $10-12$ & - & $4-5$ \\
\hline ESAB OK Band 309LMo ESW & Same & Same & $\leq 0.4$ & $19.5-21.5$ & $13-14$ & 2.8-3.3 Mo & Same \\
\hline ESAB OK Band 309LNb ESW & $»$ & $»$ & $\leq 0.4$ & $20-22$ & $11-13$ & $0.4-0.8 \mathrm{Nb}$ & 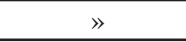 \\
\hline
\end{tabular}

Table 2. Chemical composition of fluxes for anticorrosion electroslag surfacing [6-10]

\begin{tabular}{|c|c|c|c|c|c|c|c|}
\hline \multirow{2}{*}{ Grade of flux } & \multicolumn{7}{|c|}{ Volume fraction of components, \% } \\
\cline { 2 - 9 } & $\mathrm{SiO}_{2}$ & $\mathrm{MnO}$ & $\mathrm{CaO}$ & $\mathrm{Al}_{2} \mathrm{O}_{3}$ & $\mathrm{CaF}_{2}$ & $\mathrm{FeO}$ & Other \\
\hline AN-72 & 8 & 1.0 & 30.0 & 20.0 & 30 & $\leq 2$ & $10 \mathrm{ZrO}_{2}$ \\
\hline AN-90 & $27 *$ & - & 23.5 & 10.5 & 39 & - & - \\
\hline ESAB OK 10.10 & $8 *$ & - & - & 25.0 & 63 & - & - \\
\hline ESAB OK 10.14 & $10 *$ & - & - & 20.0 & 70 & - & - \\
\hline$* \mathrm{SiO}_{2}+$ MgO.
\end{tabular}

Table 3. Chemical composition of metal deposited using electroslag method with two strips OK Band 309LNb ESW

\begin{tabular}{|c|c|c|c|c|c|c|c|c|}
\hline \multirow{2}{*}{ Number of deposited layers } & \multicolumn{8}{|c|}{ Volume fraction of elements, $\%$} \\
\hline & $\mathrm{C}$ & $\mathrm{Mn}$ & $\mathrm{Si}$ & $\mathrm{Cr}$ & $\mathrm{Ni}$ & $\mathrm{Nb}$ & $\mathrm{S}$ & $\mathrm{P}$ \\
\hline 1 & 0.014 & 1.43 & 0.67 & 22.7 & 12.5 & 0.59 & 0.005 & 0.017 \\
\hline 2 & 0.017 & 1.47 & 0.65 & 22.4 & 12.4 & 0.63 & 0.005 & 0.017 \\
\hline 3 & 0.017 & 1.42 & 0.70 & 23.1 & 12.8 & 0.58 & 0.007 & 0.019 \\
\hline
\end{tabular}

trode and the workpiece the arc appears, which melts the edges of strips, contributes to melting of flux and formation of slag pool, shunting the arc. Then the arc process is transferred into slag one, as far as current begins to run through the molten electrically conductive slag. The heating and melting of strips occurs due to heat transfer from the molten slag.

The main factors influencing the stability of electroslag process are compositions of strips and fluxes, surfacing modes and value of gap between the strips [5]. For anticorrosive surfacing at the present time a large number of surfacing materials were developed. As the electrode materials, the cold-rolled, flux-cored and sintered strips of grades Sv-08Kh19N10G2B, Np02Kh22N11G, LS-02Kh21N12G2B, ESAB OK Band 309L ESW, ESAB OK Band 309LNb ESW, etc., as well as fluxes of grades AN-72, AN-90, ESAB OK 10.10, ESAB OK 10.14 etc. are mainly applied [5, 8-10].

Moreover, the composition of flux greatly influences the quality of deposited metal [7,8]. First of all, the flux should have a high viscosity and be sufficiently «long» to provide a good formation of deposited metal. In addition, the flux should have a sufficient electric resistance, which provides generation of necessary amount of heat in the slag pool, at the same time increasing heating of electrode strips and improving efficiency of the deposition process. The chemical composition of some corrosion-resistant cold-rolled and sintered surfacing strips is shown in Tables 1 and 2 [6-10]. The presence of certain amount of $\delta$-ferrite in the austenite deposited metal provides its high resistance against crack formation [11].

In this work, strips ESAB OK Band 309LNb ESW of $0.5 \times 60 \mathrm{~mm}$ cross-section and flux ESAB OK 10.10 were used in the experiments. For comparison, in some experiments strip Sv-08Kh19N10G2B of the same section was also used. Surfacing was performed on the billets of St 3 steel of $200 \times 100 \times 30 \mathrm{~mm}$ dimensions, the current and voltage values were changed in the ranges of 1200-1600 A and 25-38 V, respectively. The deposition rate varied between $10-30 \mathrm{~m} / \mathrm{h}$, and the gap between the strips was $8-20 \mathrm{~mm}$, the stickout of the strips remained unchanged and amounted to $35 \mathrm{~mm}$.

After deposition the layer-by-layer spectral analysis of chemical composition of the deposited metal was conducted, the results of which are given in Table 3. The analysis of data, given in Tables 1 and 3, shows that in electroslag two-strip surfacing the specified chemical composition is achieved already in the first deposited layer.

The influence of current, voltage and deposition rate, as well as of gap between the strips on the stability of electroslag process, geometric sizes and VDM were investigated. It was found that sizes of the deposited 

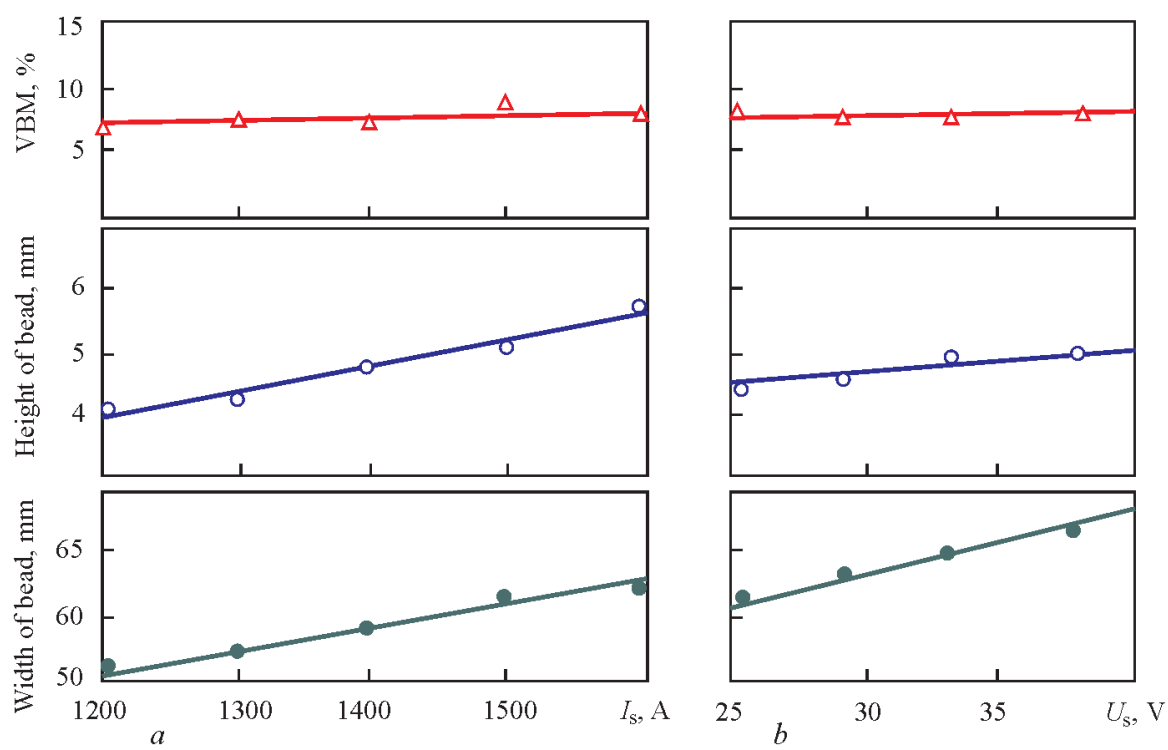

Figure 2. Influence of current ( $a$ ) and voltage $(b)$ of surfacing on geometric dimensions of deposited bead and VBM

bead are almost directly proportional to current and voltage, but VBM value remains almost unchanged (Figure 2). This is explained by the fact that during electroslag process the direct effect of arc on the base metal is absent, so increase in electric power affects mainly the increase in amount of deposited metal only.

The greater influence on VBM is provided by deposition rate, as well as the value of gap between the strips (Figure 3). The deposition rate determines duration of thermal effect of slag pool on the base metal, and the gap value significantly affects the stability of electroslag process itself.

The stability was determined by oscillograms as the ratio of duration of periods of electroslag and arc processes over the certain time. At small gap size the overheat of slag pool between the strips occurs, unsta- ble slag-arc process is observed, in connection with which the penetration of base metal is increased and formation is deteriorated. With increase in the gap the area of the slag pool surface increases, the pool temperature is reduced and the stability of electroslag process $N$ is improved (see Figure 3, b). From Figure 4 it is seen that at gap width of $16 \mathrm{~mm}$, deposited bead has a more equal edges and smoother surface than the bead produced at the same mode, but with gap width of $8 \mathrm{~mm}$.

It was found that a stable electroslag process using strips of $0.5 \times 60 \mathrm{~mm}$ section is achieved under the following surfacing parameters: $I_{\mathrm{s}}=1400-1500$ A; $U_{\mathrm{s}}=32-33 \mathrm{~V} ; v_{\mathrm{d}}=14-17 \mathrm{~m} / \mathrm{h}$; and gap between the strips of $16 \mathrm{~mm}$. Metallographic investigations showed that the specimens deposited at these modes
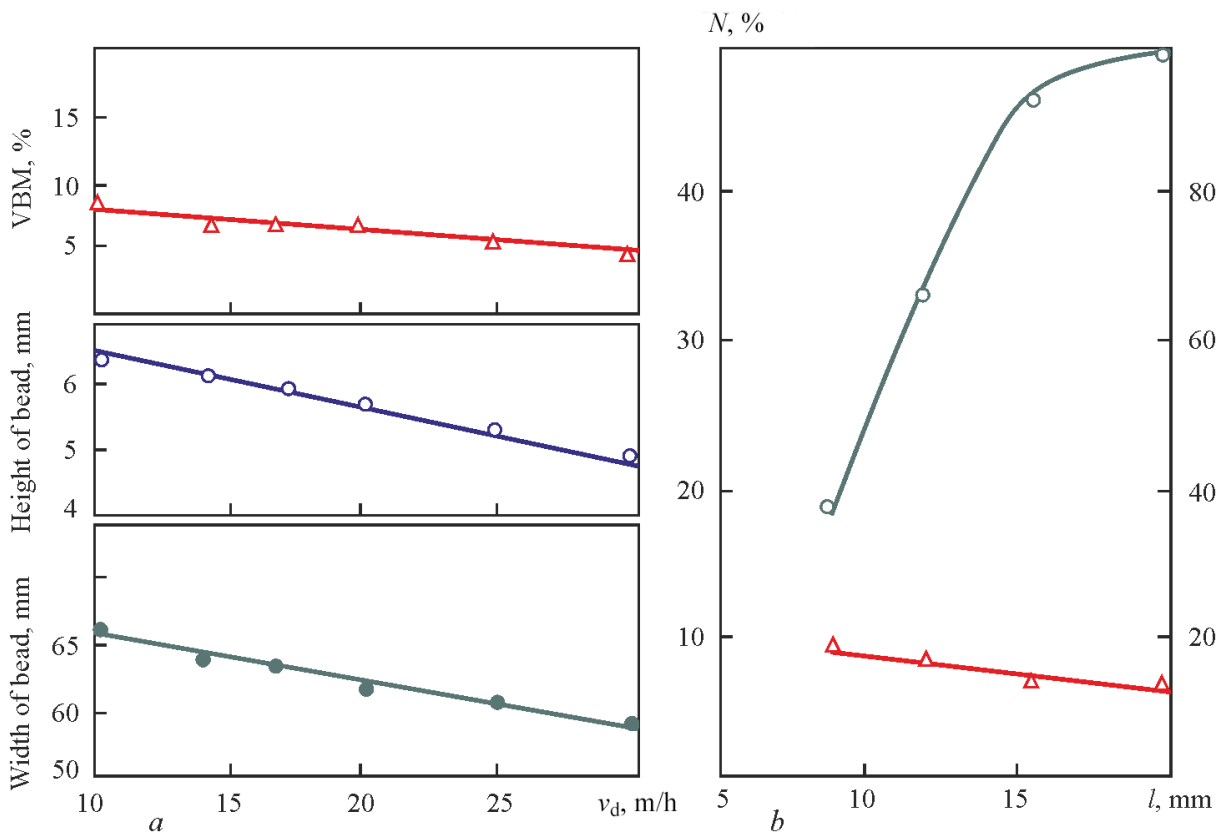

Figure 3. Influence of deposition rate ( $a$ ) and gap between the strips $(b)$ on geometric dimensions of deposited bead, VBM and process stability 
Table 4. Mechanical properties of deposited metal at $20^{\circ} \mathrm{C}$

\begin{tabular}{|c|c|c|c|c|}
\hline Deposited metal & $\sigma_{\mathrm{t}}, \mathrm{MPa}$ & $\sigma_{\mathrm{y}}, \mathrm{MPa}$ & $\delta, \%$ & $\psi, \%$ \\
\hline ESAB OK Band 309LNb & $504-506$ & $286-297$ & $44-49$ & $64.0-69.7$ \\
\hline 08Kh19N10G2B & $523-588$ & $295-314$ & $24-28$ & $52-55$ \\
\hline
\end{tabular}

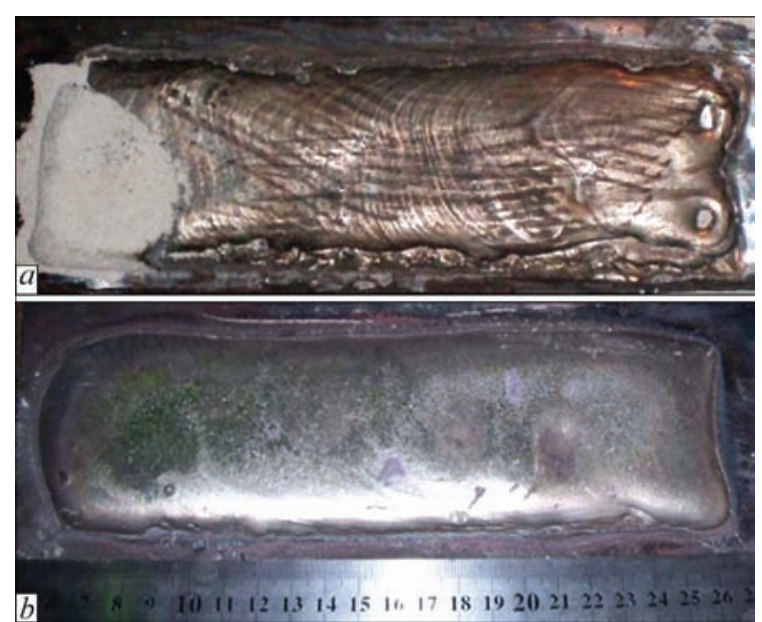

Figure 4. Influence of gap size between the strips on stability of electroslag process at $I_{\mathrm{s}}=1200-1300 \mathrm{~A}, U_{\mathrm{s}}=32-33 \mathrm{~V}, v_{\mathrm{d}}=$ $=14 \mathrm{~m} / \mathrm{h}: a-l=8 \mathrm{~mm} ; b-l=16 \mathrm{~mm}$

are characterized by a good formation of deposited metal and a minimum penetration of base metal in the ranges of 7-9 \% (Figure 5). At the same time, the fusion boundary of deposited and base metal is flat enough, that positively affects the strength properties of the produced joint.

To determine the mechanical properties of the deposited metal, multi-layer surfacing was produced at the mode mentioned above. The total thickness of deposited metal was $16 \mathrm{~mm}$, and the width was 62 $65 \mathrm{~mm}$. From the deposited billet the specimens for mechanical tests were cut out. The mechanical properties of the investigated deposited metal were determined at the temperature of $20{ }^{\circ} \mathrm{C}$ in the initial state applying tensile tests of specimens according to GOST 6996-66, the results of which are given in Table 4. For comparison, it presents also the mechanical properties of the metal deposited using electroslag two-strip method of widely used grade Sv-08Kh19N10G2B.

The test results show that the strength characteristics of the metal deposited using strips ESAB OK Band 309LNb ESW and Sv-08Kh19N10G2B are at sufficiently high level and meet the requirements specified to them. The obtained results may be used in selection or development of materials and technologies of anticorrosive surfacing of the parts of power and chemical equipment.

\section{Conclusions}

1. The range of surfacing modes using two stainless steel strips of $0.5 \times 60 \mathrm{~mm}$ section, at which a stable electroslag process with a good formation of deposited metal and minimum $7-9 \%$ penetration of base metal in the range

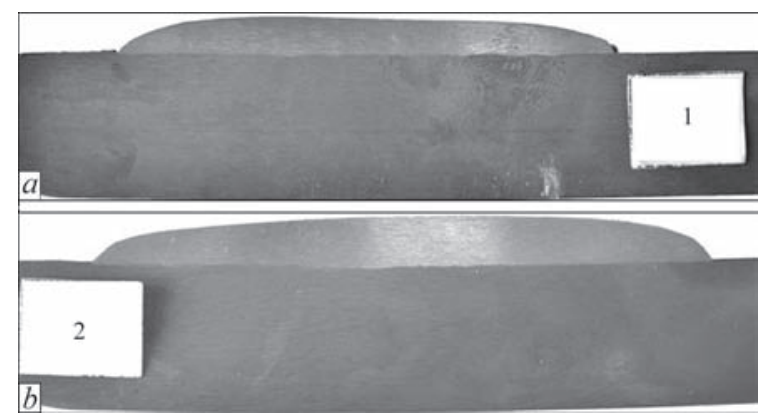

Figure 5. Macrosections of specimens deposited at two modes: $a-I_{\mathrm{s}}=1400 \mathrm{~A}(\mathrm{VBM}=7 \%) ; b-I_{\mathrm{s}}=1500 \mathrm{~A}(\mathrm{VBM}=9 \%)$, with $U_{\mathrm{s}}^{\mathrm{s}}=32-33 \mathrm{~V}, v_{\mathrm{d}}=12 \mathrm{~m} / \mathrm{h}$ and $l=16 \mathrm{~mm}$

is achieved, i.e. $I_{\mathrm{s}}=1400-1500 \mathrm{~A}, U_{\mathrm{s}}=32-33 ; v_{\mathrm{d}}=14$ $17 \mathrm{~m} / \mathrm{h}$, and $16 \mathrm{~mm}$ gap between the strips.

2. The mechanical properties of the metal deposited using electroslag method with strips ESAB OK Band 309LNb ESW and Sv-08Kh19N10G2B under flux ESAB OK 10.10 are at the sufficiently high level and meet the requirements specified to them.

1. Kravtsov, T.G. (1978) Electric arc surfacing by electrode strip. Moscow: Mashinostroenie.

2. Ryabtsev, I.A. (2005) High-efficiency wide-layer surfacing using electrode wires and strips (Review). The Paton Welding J., 6, 31-35.

3. Ivanov, V.P., Ivashchenko, V.Yu. (2011) Influence of hardfacing technology and heat treatment on structure and properties of metal deposited on carbon steel by LN-02Kh25N22AG4M2 strip electrode. Ibid., 8, 7-9.

4. Fetisov, G.P., Karpman, M.G. (2001) Materials science and technology of metals. Moscow: Vysshaya Shkola.

5. Frumin, I.I., Kalensky, V.K., Panchishin, Yu.A. et al. (1977) Development of process and examination of some technological specifics of electroslag surfacing by strips. In: Theoretical and technological principles of surfacing. New processes of mechanized surfacing, 83-88. Kiev: PWI.

6. Kalensky, V.K., Panchishin, Yu.A., Shekhteri, S.Ya. et al. (1980) Application of electroslag surfacing using sintered strips for manufacturing of double-layer sheet billets. In: Theoretical and technological principles of surfacing. Properties and tests of deposited metal, 89-92. Kiev: PWI.

7. Ignatov, V.A., Murzin, V.V., Rokhlin, E.A. et al. (1980) Study of process of electroslag anticorrosive surfacing by two-strip electrodes. In: Ibid., 101-106.

8. Buga, V.M. (1978) Development of flux and investigation of deposited metal properties with regard to single-layer surfacing of nickel-chrome alloy. In: Theoretical and technological principles of surfacing. Surfacing consumables, 95-98. Kiev: PWI.

9. Kalensky, V.K., Panchishin, Yu.A. (1985) On efficiency of anticorrosive electrode strip surfacing. In: Surfacing. Experience and efficiency of application, 35-40. Kiev: PWI.

10. Production of equipment and consumables for welding and

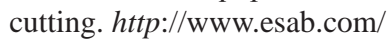

11. (1974) Technology of electric fusion welding of metals and alloys: Monograph. Ed. by B.E. Paton. Moscow: Mashinostroenie.

Received 21.01.2016 